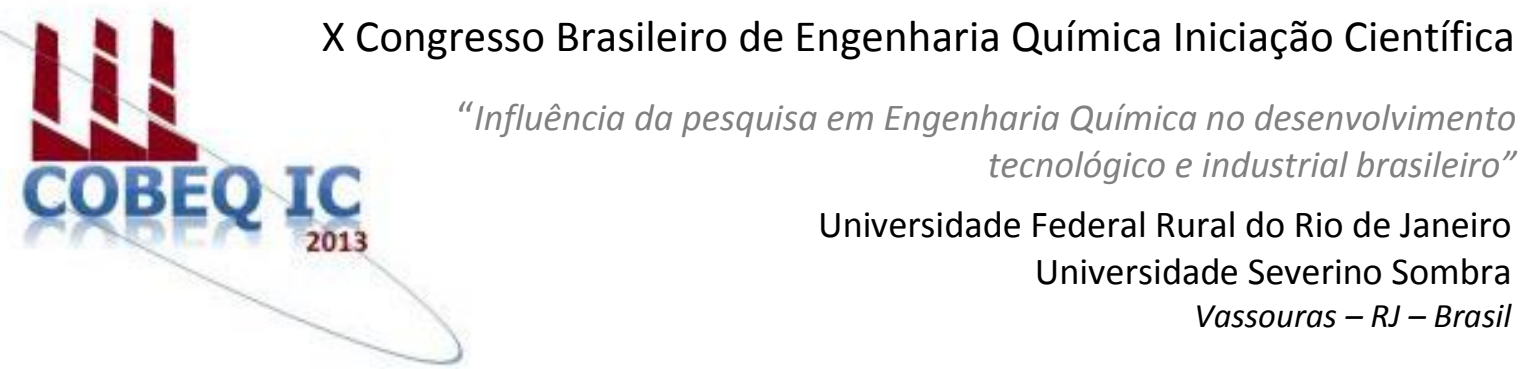

\title{
SECAGEM DE BAGAÇO DE UVA PÓS-FERMENTAÇÃO: PLANEJAMENTO EXPERIMENTAL E CINÉTICA DE SECAGEM
}

\author{
L.H. Bernardes ${ }^{1}$; K. M. Deamici ${ }^{2}$; L.C. Oliveira ${ }^{3}$ e E.G. Oliveira ${ }^{4}$ \\ Universidade Federal do Pampa - Campus Bagé \\ Endereço: Travessa 45, nº 1650, Bairro Malafaia - Campus Bagé -CEP: 96.413-170 \\ *e-mail: elizangelaoliveira@unipampa.edu.br
}

RESUMO: Vários dos subprodutos gerados pela indústria alimentícia possuem propriedades funcionais e nutricionais, o que viabiliza a utilização na elaboração e desenvolvimento de novos produtos. O bagaço da uva, subproduto da vinificação, representa cerca de $20 \%$ do peso original da fruta e o aproveitamento deste subproduto na alimentação representa uma possibilidade de agregação de valor ao subproduto, transformando-o em um alimento funcional, uma vez que é fonte de compostos fenólicos, os quais possuem propriedades anti-inflamatórias e antioxidantes. A farinha do bagaço da uva possui alto teor de flavonóides e de fibras, sendo obtida após a operação de secagem, que consiste em remover uma quantidade de umidade, mantendo certas características específicas. $\mathrm{O}$ objetivo do presente estudo foi estudar a secagem do bagaço de uva a partir de um planejamento experimental $2^{2}$ com tréplica no ponto central, avaliando a influência das variáveis temperatura e velocidade do ar de secagem na resposta umidade (base seca, b.s). A análise dos resultados obtidos pelo planejamento experimental mostrou que somente a temperatura apresentou efeito significativo sobre a resposta avaliada. A cinética de secagem apresentou os períodos de taxa constante e o decrescente. Os resultados de umidade foram na faixa de $0,035-0,329 \mathrm{~kg} . \mathrm{kg}^{-1}$ (b.s).

Palavras chave: subprodutos, farinha, umidade.

\section{INTRODUÇÃO}

Os subprodutos originários do processamento do vinho representam um problema de descarte devido ao grande volume gerado pelo mesmo. Estes subprodutos são fontes potenciais de compostos e nutrientes podendo ser aproveitados para elaboração de novos produtos (SHIEBER et al., 2001). O bagaço de uva gerado por esta indústria, destaca-se pelo elevado teor de compostos fenólicos e fibras (MAKRIS et al., 2007).

A farinha do bagaço da uva é obtida a partir da operação de secagem, a qual está entre as operações mais usuais nas indústrias químicas e de alimentos em relação à conservação dos produtos. Para a conservação de produtos agrícolas, a operação de secagem é uma das técnicas mais antigas e econômicas. Esta operação é utilizada para facilitar o manuseio de substâncias pulverulentas, diminuir o custo de transporte das matériasprimas, aumentar o valor de uma commodity para cumprir especificações a respeito da matéria prima ou de um produto (HECK, 2007).

${ }^{(1)}$ Bolsista de Iniciação Científica - FAPERGS; ${ }^{(2)}{ }^{(3)}$ Engenheira(o) de Alimentos; ${ }^{(4)}$ Docente - 
Essas vantagens estão relacionadas, de uma forma geral, ao encolhimento que os produtos biológicos sofrem durante a secagem, devido à utilização de altas temperaturas e, por consequência, o abaixamento do teor de umidade. As temperaturas que o produto é submetido juntamente com o fenômeno de encolhimento e propriedades físicas, como a massa específica, são o fundamento para a modelagem matemática do processo de secagem (GABAS, 1998).

$\mathrm{O}$ alto teor de fibras contido nesses subprodutos beneficia a saúde no que diz respeito à redução do colesterol e melhora no trânsito intestinal, dentre outros benefícios.

Baseado neste contexto, o presente estudo teve como objetivo estudar a operação de secagem do bagaço de uva a partir de um planejamento experimental $2^{2}$ com tréplica no ponto central, avaliando a influência das variáveis temperatura e velocidade do ar de secagem na resposta umidade (base seca).

\section{MATERIAIS E MÉTODOS}

\section{Subproduto - bagaço de uva}

$O$ bagaço de uva fermentado foi fornecido pela Vinícola Peruzzo (safra 2011/2013) localizada na cidade de Bagé. O subproduto recebido foi armazenado em sacos plásticos e acondicionado à temperatura de $18^{\circ} \mathrm{C}$ em freezer. Antes da realização da secagem, a amostra foi colocada em um refrigerador a $4^{\circ} \mathrm{C}$ por $24 \mathrm{~h}$, a fim de obter homogeneidade de temperatura. A amostra utilizada para secagem foi lavada em água corrente para retirar a possíveis sujidades presentes. A umidade inicial e final das amostras foi determinada através do método da AOAC (1995), em que a amostra é submetida à temperatura de $105^{\circ} \mathrm{C}$ por $24 \mathrm{~h}$.

\section{Operação de secagem}

A secagem foi realizada em um secador de leito fixo em túnel, localizado no Laboratório de Engenharia Química da Universidade Federal do Pampa.

A fim de avaliar a influência da temperatura e da velocidade do ar na operação de secagem do bagaço da uva, foi empregado um planejamento fatorial $2^{2}$ com tréplica no ponto central, totalizando sete ensaios de secagem. As variáveis independentes definidas no processo foram: temperatura $(\mathrm{T})$ e a velocidade do ar de secagem (v) (Tabela 1) e como variável de dependente (resposta), a umidade em base seca $\left(\mathrm{U}_{\mathrm{bs}}\right)$. O tempo de duração de cada ensaio foi fixado em $140 \mathrm{~min}$. Os níveis das variáveis, assim como o tempo total de secagem foram definidos em testes preliminares de secagem e análises em trabalhos similares.

Tabela 1- Níveis e fatores codificados utilizados no planejamento experimental

\begin{tabular}{ccc}
\hline Variáveis & $\begin{array}{l}\text { Temperatura } \\
\left({ }^{\circ} \mathrm{C}\right)\end{array}$ & $\begin{array}{l}\text { Velocidade } \\
\text { do ar }(\mathrm{m} / \mathrm{s})\end{array}$ \\
Niveis & 50 & 1,0 \\
-1 & 60 & 1,5 \\
0 & 70 & 2,0 \\
\hline
\end{tabular}

Após o término dos experimentos, os resultados do planejamento fatorial foram avaliados através de um software estatístico.

A secagem, através do planejamento experimental (Tabela 2), foi realizada em um secador de túnel com as condições do ar de secagem controladas. As amostras foram distribuídas em bandeja de alumínio perfuradas, com formato circular com diâmetro de $15 \mathrm{~cm}$, previamente secas, no interior do secador de túnel. Durante a secagem, obteve-se o valor da massa de amostra em intervalos de tempos regulares de 3 min, para estudo da cinética de secagem. As curvas de caracterização da secagem foram obtidas com os dados de massa da amostra, realizada numa balança com precisão de $0,01 \mathrm{~g}$ acoplada ao secador.

Tabela 2 - Matriz de planejamento

\begin{tabular}{ccc}
\hline Ensaio & \multicolumn{2}{c}{ Variáveis dependentes } \\
\cline { 2 - 3 } & $\mathrm{T}\left({ }^{\circ} \mathrm{C}\right)$ & $\mathrm{v}(\mathrm{m} / \mathrm{s})$ \\
\hline 1 & 50 & 1 \\
2 & 70 & 1 \\
3 & 50 & 2 \\
4 & 70 & 2 \\
5 & 60 & 1,5 \\
6 & 60 & 1,5 \\
7 & 60 & 1,5 \\
\hline
\end{tabular}


A influência das variáveis independentes $\left(\mathrm{T}\right.$ e v) sobre a variável resposta $\left(\mathrm{U}_{\mathrm{bs}}\right)$ foi avaliado por métodos estatísticos, através da análise de variância (ANOVA) e superfície de resposta.

\section{RESULTADOS E DISCUSSÕES}

O conteúdo de umidade média inicial do bagaço de uva, obtido pelo método da AOAC (1995), foi de $1,76 \mathrm{~kg} \cdot \mathrm{kg}^{-1}$, em base seca (b.s). A matriz do planejamento utilizado neste trabalho está apresentada na Tabela 3

Tabela 3 - Matriz com as variáveis codificadas e reais e a variável resposta do planejamento experimental

\begin{tabular}{cccccc}
\hline Ensaio & $\mathrm{T}_{\text {cod }}$ & $\mathrm{T}_{\text {real }}\left({ }^{\circ} \mathrm{C}\right)$ & $\mathrm{V}_{\text {cod }}$ & $\begin{array}{l}\mathrm{V}_{\text {real }} \\
(\mathrm{m} / \mathrm{s})\end{array}$ & $\begin{array}{l}\mathrm{U}_{\text {final }} \\
(\mathrm{b} . \mathrm{s})\end{array}$ \\
\hline 1 & -1 & 50 & -1 & 1,0 & 0,329 \\
2 & +1 & 70 & -1 & 1,0 & 0,139 \\
3 & -1 & 50 & +1 & 2,0 & 0,289 \\
4 & +1 & 70 & +1 & 2,0 & 0,035 \\
5 & 0 & 60 & 0 & 1,5 & 0,181 \\
6 & 0 & 60 & 0 & 1,5 & 0,091 \\
7 & 0 & 60 & 0 & 1,5 & 0,132 \\
\hline
\end{tabular}

T: Temperatura de secagem; v: Velocidade do ar de secagem; $\mathrm{U}_{\text {final }}$ : Umidade final da amostra em base seca.

Pode-se verificar através da Tabela 3 que os valores da $U_{\text {final }}$ (b.s) variam de 0,035 a $0,329 \mathrm{~kg} \cdot \mathrm{kg}^{-1}$, após o tempo total de secagem de $140 \mathrm{~min}$.

\section{Análise dos efeitos}

A Figura 1 apresenta os efeitos das variáveis de estudo na resposta, considerando as interações entre as variáveis com um intervalo de confiança de $95 \%$. Os dados foram obtidos considerando erro puro. A variável independente que obteve influência sobre a resposta foi a temperatura. A magnitude dos efeitos é representada pelas colunas, enquanto que a linha transversal às colunas representa a magnitude dos efeitos com significado estatístico no intervalo -de confiança de $95 \%$ e nível de significância $(\alpha)$ de 0,05 .
Figura 1- Diagrama de Pareto

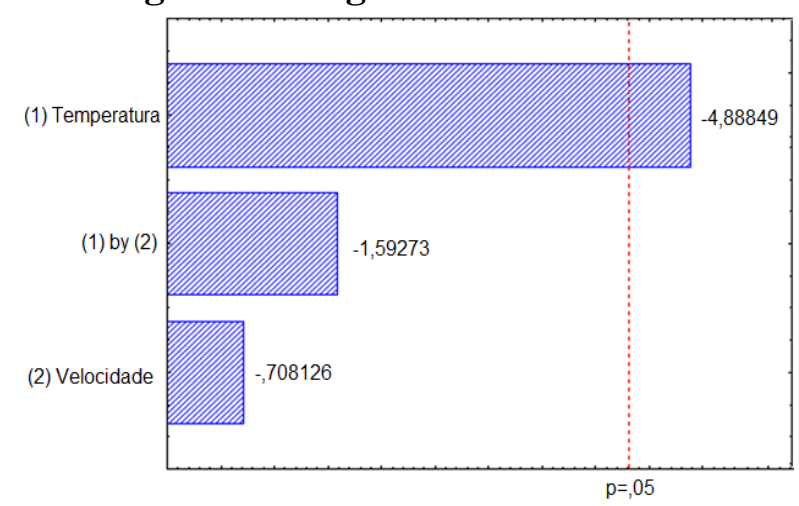

Os valores dos efeitos estimados indicam quanto cada fator influencia na variável resposta e quanto maior é seu valor, maior é sua influência. Um efeito positivo indica que ao passar de um valor mínimo a um máximo da variável, a resposta aumenta. Já o efeito negativo, como o ocorrido neste trabalho, indica o contrário, ao passar de um valor mínimo para o valor máximo, a resposta diminui.

Pelo Diagrama de Pareto (Figura 1) é possível observar o efeito da variável temperatura sobre a resposta, influenciando de forma significativa, uma vez que a linha transversal às colunas passa apenas pela coluna representativa da variável temperatura. O valor negativo $(-4,88849)$ indica que ao aumentar a temperatura do valor mínimo $\left(50^{\circ} \mathrm{C}\right)$ para o valor máximo $\left(70^{\circ} \mathrm{C}\right)$, acarreta uma diminuição no valor da resposta.

\section{Análise de variância}

Eliminando-se os fatores não significativos (velocidade do ar e interação entre as duas variáveis), foi construída a Tabela 4 para realizar a análise de variância, que consiste na avaliação do coeficiente de determinação $\mathrm{R}^{2}$ e do teste $\mathrm{F}$, a fim de verificar se o modelo representa um grau de ajuste adequado aos dados experimentais.

Tabela 4- Análise de Variância dos fatores significativos.

\begin{tabular}{ccclcc} 
FV & SM & GL & MQ & F & $F_{\text {tab }}$ \\
\hline Regressão & 491,06 & 1 & 491,06 & 13,9 & 10,1 \\
Resíduos & 174,44 & 5 & 35,08 & & \\
Falta de ajuste & 133,34 & 3 & 44,44 & 2,16 & 19,1 \\
Erro puro & 41,09 & 2 & 20,54 & & \\
Total & 665,509 & 6 & & & \\
FV: Fonte de variação; SM: Soma dos quadrados; GL: Graus de \\
liberdade; MQ: média quadrática
\end{tabular}


Observando-se a Tabela 4, fica evidente que o modelo obtido é preditivo, uma vez que o $F_{\text {cal }}$ entre a regressão e o resíduo $(13,9)$ mostrou-se superior ao $F_{\text {tab }}(10,1)$, de acordo com a tabela do teste de Fisher com nível de significância de 5\% apresentada por Costa Neto (2002). Outra relação importante para observar a validade do modelo é a relação entre o $F_{\text {cal }}$ da falta de ajuste e do erro puro, que deve ser inferior ao valor do $F_{\text {tab }},\left(F_{\text {cal }} 2,1\right.$ $\left.<\mathrm{F}_{\text {tab }} 19,1\right)$. O coeficiente de determinação $\left(\mathrm{R}^{2}\right)$ para o modelo ajustado foi de 0,737 .

A partir dos parâmetros estatisticamente significativos $(p<0,05)$, obteve-se o modelo matemático codificado apresentado na Equação 1, onde $U$ corresponde à umidade final e $\mathrm{T}$ à temperatura de secagem.

$U=17,108-11,08 . T$

A partir do modelo matemático codificado reduzido (Equação 1), foi construída a superfície de resposta, apresentada na Figura 2.

\section{Figura 2 - Superfície de resposta}

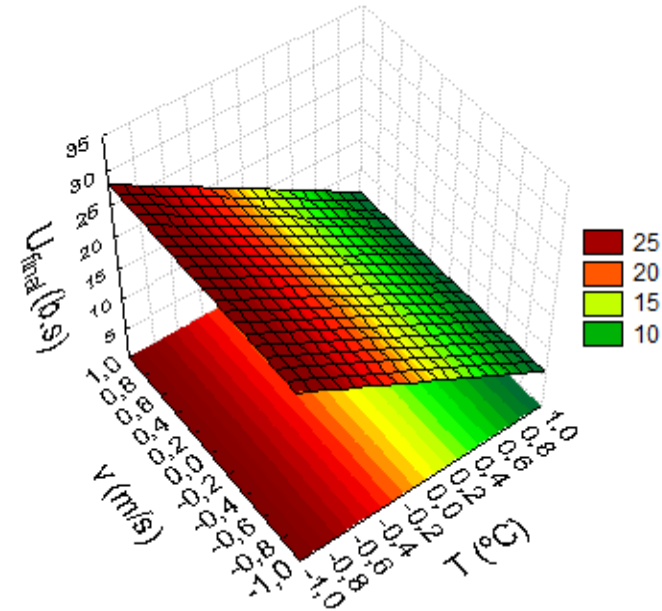

De acordo com a Figura 2, verifica-se que a umidade final (b.s) decresce com o aumento da temperatura e a velocidade do ar de secagem não influencia no valor da umidade final (b.s).

A Resolução - CNNPA n ${ }^{\circ}$ 12, de 1978 estabelece teor máximo de umidade para farinhas no máximo de $15 \%$ (b.u), que corresponde em base seca (b.s) ao valor de aproximadamente $0,18 \mathrm{~kg} \cdot \mathrm{kg}^{-1}$. Na Figura 2, este valor se encontra na zona de coloração laranja relacionando ao eixo $\mathrm{Y}$ ( $\mathrm{U}_{\text {final }}($ b.s $)$ ). Desta forma, a temperatura de secagem que alcançou este percentual foi superior à temperatura média estudada, neste caso, $70^{\circ} \mathrm{C}$. Como pode ser observado na Figura 2, valor da umidade final abaixo de $15 \%$ se encontra nas zonas de coloração verde, acima do ponto central. Dessa forma, a melhor condição de secagem obtida através da superfície de resposta é com temperatura de $70^{\circ} \mathrm{C}$ e, uma vez que a velocidade do ar não influenciou no processo, foi escolhida $1 \mathrm{~m} / \mathrm{s}$.

\section{Cinética de secagem}

A secagem do bagaço de uva foi caracterizada pelas curvas apresentadas na Figura 3 (a) e (b). A primeira relaciona a forma adimensional do conteúdo de umidade $(\mathrm{X}-\mathrm{Xe}) /\left(\mathrm{X}_{0}-\mathrm{Xe}\right)$ e o tempo total que ocorreu a secagem. Esta curva foi obtida pelos dados experimentais dos ensaios e representa a diminuição do teor de umidade ao longo do tempo. Já a segunda curva, é uma derivação da primeira, no qual fornece as mesmas informações, porém relaciona a taxa de secagem por área (NA) pelo teor de umidade obtido ao longo do tempo.

\section{Figura 31 - Curvas características da secagem obtida após o planejamento experimental}

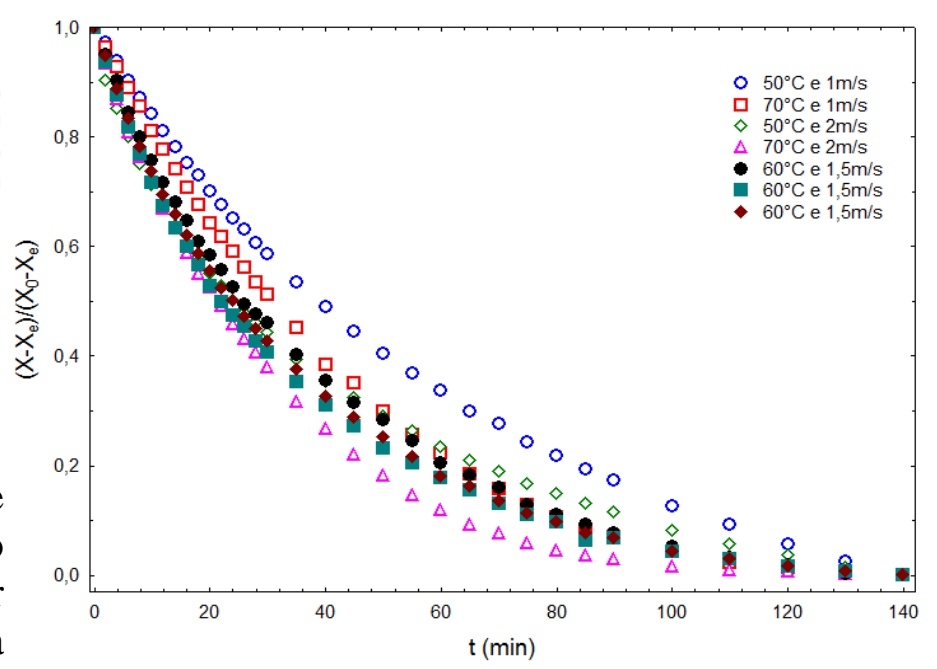

(a) 


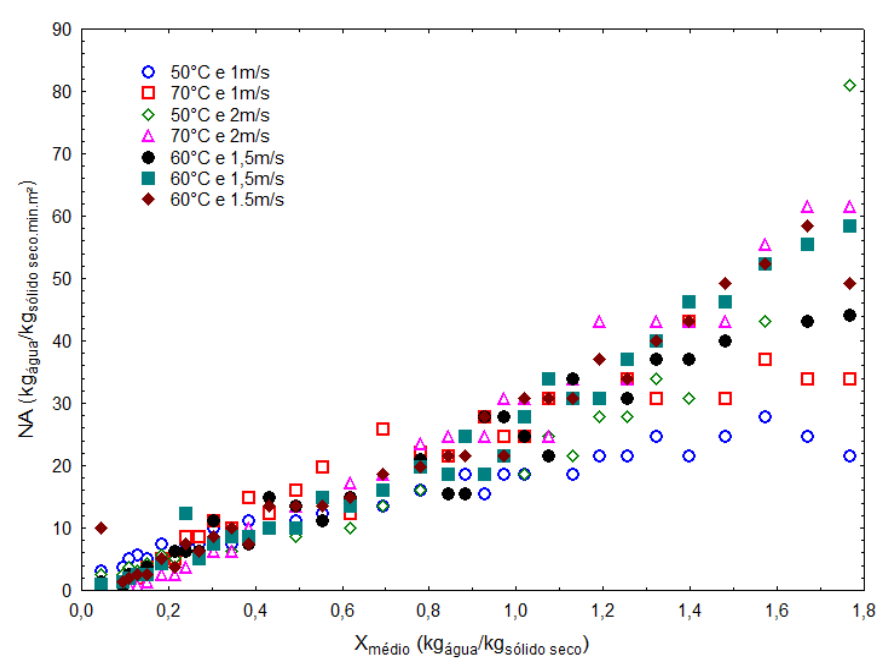

(b)

Mediante os resultados apresentados nas Figuras 3 (a) e (b) é possível observar os dois períodos distintos de secagem, o período de taxa constante e o período de taxa decrescente. $\mathrm{O}$ primeiro período teve duração de aproximadamente 40 min (Figura 3-a), seguido da taxa decrescente que se estende até o final da secagem. Este fenômeno pode ser observado também na Figura 3 (b), onde os três primeiros pontos apresentados nessa figura, nas diferentes temperaturas, correspondem à taxa constante e após iniciou a taxa decrescente de secagem. Outro fato importante observado nas curvas de secagem é a comprovação da influência apenas da variável temperatura no estudo, pois no início da secagem à temperatura de $70^{\circ} \mathrm{C}$, ocorre a retirada de água do material mais rapidamente que durante a secagem a $50^{\circ} \mathrm{C}$ e a estabilização do teor de umidade da amostra a $70^{\circ} \mathrm{C}$ se dá mais rápido que a $50^{\circ} \mathrm{C}$, como pode ser observado na Figura 3 (a). Na temperatura mais elevada essa estabilização inicia em aproximadamente $80 \mathrm{~min}$ enquanto que na temperatura inferior, iniciou em $130 \mathrm{~min}$.

\section{CONCLUSÃO}

$\mathrm{O}$ fator temperatura influenciou a resposta, tendo efeito negativo sobre a mesma, ou seja, com o aumento da temperatura reduziu o teor de umidade. Dessa forma, a melhor condição de secagem para obter o teor de umidade adequado para farinhas foi a temperatura de $70^{\circ} \mathrm{C}$ e velocidade do ar de secagem de $1 \mathrm{~m} / \mathrm{s}$. A cinética de secagem do bagaço de uva na melhor condição proposta apresentou dois períodos distintos, o primeiro com duração de $40 \mathrm{~min}$ determinado como período de taxa constante, seguido da taxa decrescente que se estendeu até o final da secagem.

\section{REFERÊNCIAS}

BRASIL. Agência Nacional de Vigilância Sanitária - ANVISA. Resolução CNNPA $n^{\circ}$ 12, de janeiro de 1978 Farinhas. Disponível em: <http://www.anvisa.gov.br/legis/resol /12_78_farinhas.htm>. Acesso em: $1^{\circ}$ de nov. 2012.

GABAS, A. L. Secagem da Uva Itália em Leito Fixo. Universidade Estadual de Campinas (Dissertação de Mestrado) Campinas - SP, p.2-4, 1998.

HECK, N. C. Metalurgia Extrativa dos Metais Não-Ferrosos. Universidade Federal do Rio Grande do Sul (UFRGS), Departamento de Engenharia Metalúrgica (Material Didático), Porto Alegre - RS, p.1-2, 2007.

MAKRIS, D. P.; BOSKOU, G.; ANDRIKOPOLOUS, N. K. "Polyphenolic Content and in vitro Antioxidant Characteristics of Wine Industry and Other Agri-Food Solid Waste Extracts." Journal of food composition and analysis, San Diego, v.20, p.125-132, 2007.

COSTA NETO, P. L. O. Estatística. São Paulo, Edgard Blücher, 2002.

SHIEBER, D. F.; STINTZING, C.; CARLE, R. "By-produtcs of Plant Food Processing as Sourtve of Functional CompoundsRecent Developments." Trend Food Sci Technol; v. 12, p.401-413, 2001.

\section{AGRADECIMENTOS}

À FAPERGS, pelo apoio financeiro. 
